\title{
Глиадины: структура и токсичные эпитопы
}

\author{
Н.А. Виниченко ${ }^{1,2} \bowtie$ Е.А. Салина ${ }^{1,2}$
}

\begin{abstract}
Аннотация: В обзоре показаны особенности структуры глиадинов, а также распределение эпитопов, связанных с целиакией, среди глиадинов разных типов. Рассмотрено несколько приоритетных подходов, позволяющих ускорить создание сортов пшеницы с улучшенным составом глютена (клейковины), безопасного для здоровья.
\end{abstract}

Ключевые слова: пшеница; глютен (клейковина); структура глиадинов; эпитопы целиакии.

Благодарности: Работа поддержана бюджетным проектом № 0259-2021-0012.

Для цитирования: Виниченко Н.А., Салина Е.А. Глиадины: структура и токсичные эпитопы. Письма в Вавиловский журнал генетики и селекции. 2021;7(4):163-171. DOI 10.18699/LettersVJ2021-7-21

\section{Gliadins: structure and toxic epitopes}

N.A. Vinichenko ${ }^{1,2}{ }_{凶}$ E.A. Salina ${ }^{1,2}$

Abstract: This review shows features of the gliadins structure and the distribution of epitopes associated with celiac disease, among gliadins of different types. Several priority approaches were considered to accelerate the development of wheat varieties with an improved composition of gluten, safe for health.

Key words: wheat; gluten; gliadins structure; celiac disease epitopes.

For citation: Vinichenko N.A., Salina E.A. Gliadins: structure and toxic epitopes. Pisma v Vavilovskii Zhurnal Genetiki i Selektsii = Letters to Vavilov Journal of Genetics and Breeding. 2021;7(4):163-171. DOI 10.18699/LettersVJ2021-7-21 (in Russian)

\section{Введение}

Известно, что свойства пшеничного зерна, которые позволяют использовать его для выпекания хлеба, обеспечиваются двумя разновидностями глютенообразующих запасных белков эндосперма: растворимых в спирте глиадинов и глютенинов, растворимых в разбавленных кислотах и основаниях (Osborne, 1907; Труфанов, 1994; Wieser, 2007; Singh et al., 2011). Считается, что на пластичность и растяжимость глютена (клейковины) влияют глиадины, а глютенины обеспечивают вязкость, эластичность и прочность глютена (Rodrigues et al., 2005). Отношение количества глютенинов к количеству глиадинов регулирует прочность и растяжимость теста (Wrigley et al., 2006).
Глиадины составляют 40-50 \% общего запасного белка (Anderson et al., 1997). Они содержат большое количество остатков пролина (P) и глутамина (Q), но отличаются низким содержанием лизина (К). В глютенинах содержание лизина выше, чем в глиадинах. Вместе глиадины и глютенины составляют 80-85 \% от общего количества белков пшеничной муки (Veraverbeke, Delcour, 2002). В состав глютеновых полипептидов входят субъединицы глютенина с высокой молекулярной массой (HMW-GS: 90-140 кДа) и субъединицы с низкой молекулярной массой (LMW-GS: 30-75 кДа). Остатки цистеина субъединиц HMW-GS образуют внутрицепочечные дисульфидные связи, значительно стабилизирующие полимеры глютена (Lefebvre, Mahmoudi, 2007).

\footnotetext{
1 Федеральный исследовательский центр Институт цитологии и генетики Сибирского отделения Российской академии наук, Новосибирск, Россия Institute of Cytology and Genetics of the Siberian Branch of the Russian Academy of Sciences, Novosibirsk, Russia

2 Курчатовский геномный центр ИЦиГ СО РАН, Новосибирск, Россия Kurchatov Genomic Center of ICG SB RAS, Novosibirsk, Russia

凶vinia@bionet.nsc.ru

(C) Виниченко Н.А., Салина Е.А., 2021
} 
Глиадины - мономерные белки с молекулярным весом 30000-75000 Да, при гидратации ведущие себя как вязкая жидкость (Singh, Khatkar, 2005; Song, Zheng, 2008). Вязкость мономерных глиадинов обеспечивается посредством нековалентных взаимодействий, таких как водородная связь, вандерваальсовы взаимодействия, электростатические и гидрофобные взаимодействия. Кроме того, глиадины могут также взаимодействовать с глютениновыми полимерами посредством нековалентных гидрофобных взаимодействий и с глутаминовыми остатками - посредством водородных связей (Wellner et al., 2003).

В настоящее время для разделения глиадиновых компонентов и идентификации сортов пшеницы широко используют различные способы электрофореза и хроматографии. Согласно современной классификации выделяют

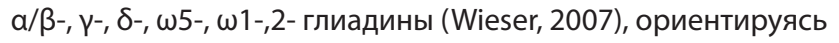
на электрофоретическую подвижность. Известно, что $\alpha / \beta-$ глиадины обладают наибольшей электрофоретический подвижностью, а $\omega$-глиадины - наименьшей. Из-за структурной гомологии, выявленной при аминокислотном секвенировании, a- и $\beta$-глиадины часто объединяют в одну группу (Barak et al., 2015). Исследование аминокислотных последовательностей показало родственность а- и ү-глиадинов c LMW-GS (Veraverbeke, Delcour, 2002). Омега-глиадины разделяются на $\omega-1, \omega-2$ и $\omega-5$ типы. Типы $\omega-1$ и $\omega-2$ имеют сходный аминокислотный состав и N-концевые последовательности, кодируются хромосомами 1A и 1D. Тип $\omega-5$ содержит больше глутамина и имеет другую N-концевую последовательность, кодируется хромосомой 1B (DuPont et al., 2004).

Генотип мягкой пшеницы кодирует более 50 различных полипептидов глиадина. Синтез глиадинов у мягкой пшеницы контролируется шестью основными локусами: Gli-A1, Gli-B1, Gli-D1, расположенными в дистальной части коротких плеч хромосом гомеологической группы 1; Gli-A2, Gli-B2, Gli-D2, картированными в дистальной части коротких плеч хромосом гомеологической группы 6 (Metakovsky et al., 2021). Каждый Gli-аллель кодирует два или более полипептидов глиадина (блок электрофоретических полос), которые наследуются совместно. Гены, кодирующие $\gamma^{-}, \omega$ - или $\delta$-глиадины, расположены преимущественно в локусах Gli1 , тогда как гены всех a/ $\beta$ - и некоторых $\gamma$-глиадинов находятся в локусах Gli-2. Основные локусы глиадинов являются мультигенными, что осложняет их изучение (Qi, 2006).

Установлено, что глиадины могут вызывать возникновение целиакии (celiac disease - CD) у генетически восприимчивых индивидуумов. Пептиды глиадина, стимулирующие CD, как правило, содержат один или несколько антигенных детерминант (эпитопов), способных связываться с Т-клетками человека. Эпитопы, например 33-мерный токсичный пептид а-глиадина LQLQPFPQPQLPYPQPQLPYPQPQLPYPQPQ PF, обычно богаты пролином и глутамином, и высокое содержание пролина делает их устойчивыми к расщеплению протеазами (Sollid, 2000; du Pré, Sollid, 2015; Stamnaes, Sollid, 2015). Такие эпитопы также присутствуют в HMW-GSs и LMW-GSs, но в меньшем количестве (Shewry, Tatham, 2016). Эти эпитопы связываются со специфическими гаплотипами белков лейкоцитарного антигена человека (HLA) II класса, то есть HLA-DQ2.2, HLA-DQ2.5, HLA-DQ8 и HLA-DQ8.5, экспрес- сируемых на поверхности CD4 + Т-клеток (Wang et al., 2017). Это вызывает сложные биохимические и биологические события в клетке, ведущие к разрушению эпителиальных клеток и атрофии ворсинок в тонком кишечнике (Sollid, 2000; du Pré, Sollid, 2015; Stamnaes, Sollid, 2015). При целиакии обычно происходит нарушение всасывания дисахаров, жиров, витаминов, железа, кальция; а также нарушаются транспорт цистина и обмен триптофана. У пациентов с целиакией повышается вероятность развития Т-клеточной лимфомы и остеопороза (Tack et al., 2010). В обзоре рассмотрены структура различных типов глиадинов, а также токсичность некоторых из них.

\section{Структура и аминокислотный состав глиадинов}

Первичная структура глиадиновых белков имеет большое значение, поскольку они, будучи детерминантами качества муки, влияют на развитие пищевой целиакии (Wang et al., 2017). В типичном глиадиновом протеине после сигнальной последовательности присутствуют пять доменов (Barak et al., 2015) (рис. 1):

(I) N-концевой домен.

(II) Домен повторов, он богат глутамином и состоит из умеренно консервативных повторов длиной 5-7 аминокислот (АК). (В а-глиадинах полиглутаминовую последовательность в конце этого домена некоторые исследователи (Noma et al., 2016) выделяют в отдельный полиглутаминовый домен.)

(III) Уникальный домен.

(IV) Полиглутаминовый домен размером 7-28 аминокислот. (В сорте пшеницы Cheyenne идентифицирован необычный а-глиадиновый ген, содержащий полиглутаминовый домен длиной 107 аминокислот (Noma et al., 2016).)

(V) Уникальный домен.

Вторичная структура молекул разных типов глиадинов отличается. По последним данным, $\alpha / \beta$-глиадины имеют компактные глобулярные структуры, а $\gamma^{-}$и $\omega$-глиадины удлиненные и стержнеобразные структуры (Paananen et al., 2006; Ang et al., 2010).

Альфа- и бета-глиадины

Эти два типа белков глиадинов имеют сходные первичные структуры, состоящие приблизительно из 250 и 300 остатков аминокислот. Первичная структура а/ $\beta$-глиадинов (см. рис. 1) содержит сигнальный пептид (20 аминокислот); короткий N-терминальный домен (5 аминокислотных остатков); домен с повторами, содержащий богатые пролином и глутамином повторяющиеся последовательности: гептапептид P-Q-P-Q-P-F-P и пентапептид P-Q-Q-P-Y (Ferranti et al., 2007). Некоторые авторы выделяют из состава этого домена отдельный полиглутаминовый домен, уникальный домен, полиглутаминовый домен и уникальный С-терминальный домен. Альфа-глиадины в своих уникальных доменах (III, V) содержат шесть остатков цистеина, которые образуют три внутрицепочечные перекрестные связи (Altenbach et al., 2010). Также сообщалось об а-глиадинах с нечетным числом остатков цистеина (Anderson et al., 1997). Такие глиадины могут образовывать одну межмолекулярную S-S связь и 


\begin{tabular}{l}
\multicolumn{2}{l}{$\alpha$-gliadin } \\
$\mathrm{H}_{2} \mathrm{~N}-\mathrm{SIG} / \mathrm{I}$ \\
\cline { 2 - 5 }
\end{tabular}

\begin{tabular}{l|l|l|l|l|l|l|}
\multicolumn{1}{l|}{$\gamma$-gliadin } \\
$\mathrm{H}_{2} \mathrm{~N}$
\end{tabular}

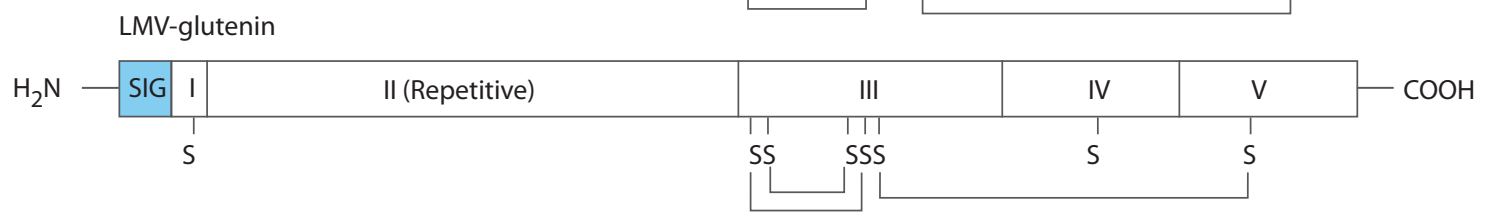

$\omega$-gliadin

\begin{tabular}{l|l|l|}
$\mathrm{H}_{2} \mathrm{~N}-\mathrm{SIG}$ & Repetitive & $\mathrm{COOH}$ \\
\hline
\end{tabular}

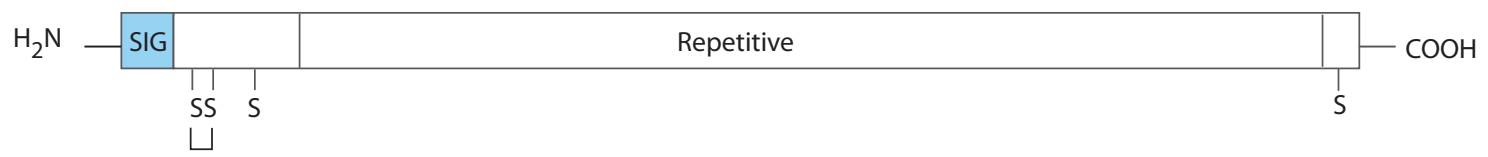

Рис. 1. Общая структура глиадинов и глютенинов пшеницы. Схематично показаны домены основной последовательности, консервативные цистеиновые остатки (S) и внутримолекулярные дисульфидные связи (линии, соединяющие Ss). Сигнальные пептиды (SIG) отмечены синим цветом. Схематически полипептидная цепь $\beta$-глиадина соответствует а-глиадину, а $\delta$-глиадина - $\gamma$-глиадину. Зрелая полипептидная последовательность $\alpha / \beta$ - и $ү$-глиадинов, а также LMW-глютенинов состоит из пяти секций: I - короткий неповторяющийся пептид (N-концевой домен), II - повторяющийся домен, состоящий из вариаций коротких мотивов, III - неповторяющаяся область, содержащая большинство остатков цистеина, IV - богатый глутамином домен и V - неповторяющийся С-концевой домен. Омега-глиадины обычно не имеют цистеинов и, следовательно, дисульфидных связей (по: Anderson et al., 2012)

действовать как терминаторы синтеза глютенина и, вероятно, уменьшать молекулярный вес полимерной цепи глютенина (Kajendran et al., 2019; Noma et al., 2016).

\section{Гамма-глиадины}

Полипептид ү-глиадина состоит из ряда доменов (см. рис. 1): сигнальной последовательности (20 остатков); далее $\mathrm{N}$-концевой пептид (12 аминокислот), за ним следует домен повторов (домен II), состоящий главным образом из пролина и глутамина, заявленной типичной единицей $ү$-глиадинов является $\mathrm{PFPQ}_{1-2}(\mathrm{PQQ})_{1-2^{\prime}}$ повторов может быть 7-22. Далее располагаются уникальные последовательности (домены III и V) с включениями нерегулярных повторов и отделенные друг от друга полиглутаминовым доменом, состоящим из 6-16 аминокислот (домен IV) (Qi et al., 2009). Большая часть цистеиновых остатков (6 из 8), образующих дисульфидные связи, находится в III домене. В настоящее время клонировано и изучено более 340 генов, кодирующих $ү$-глиадины (Metakovsky et al., 2019). Известно, что эти гены различаются по количеству повторений в домене II, нуклеотидным замещениям и малым делециям и инсерциям, а также по длине домена IV (Metakovsky et al., 2019). Таким образом, a-, $\beta$ - и $\gamma$ - глиадины имеют возможность большего взаимодействия с глютенином из-за большего количества остатков цистеина по сравнению с $\omega$-глиадинами.

\section{Омега-глиадины}

Омега-глиадины имеют больший молекулярный вес, чем другие глиадины, - от 41.0 до 51.5 кДа. Большинство из них также более кислые, чем другие глиадины, с pl от 4.68 до 6.16. Общая структура белка $\omega$-глиадина включает: сигнальный пептид (19 аминокислотных остатков), далее $\mathrm{N}$-концевой домен (10-11 остатков), домен повторов, охватывающий 90-96 \% белка, и С-концевой домен (10-11 остатков) (см. рис. 1).

Остатки пролина (P), глутамина (Q) и фенилаланина (F) составляют $80 \%$ от общего количества аминокислот в w-глиадинах по сравнению с 50-60 \% для других глиадинов (Hisa, Anderson, 2001). Они также могут содержать незначительное количество метионина (М) и цистеина (C) (серосодержащих АК) или не содержать их. По этой причине $\omega$-глиадины не способны создавать внутрицепочечные дисульфидные связи и формировать компактную структуру. Эти глиадины имеют мало заряженных АК, таких как лизин (K), гидрофобность их поверхности ниже, чем у а- и $\mathrm{\gamma}$-глиадинов. Были обнаружены $\omega$ - глиадины, имеющие один 


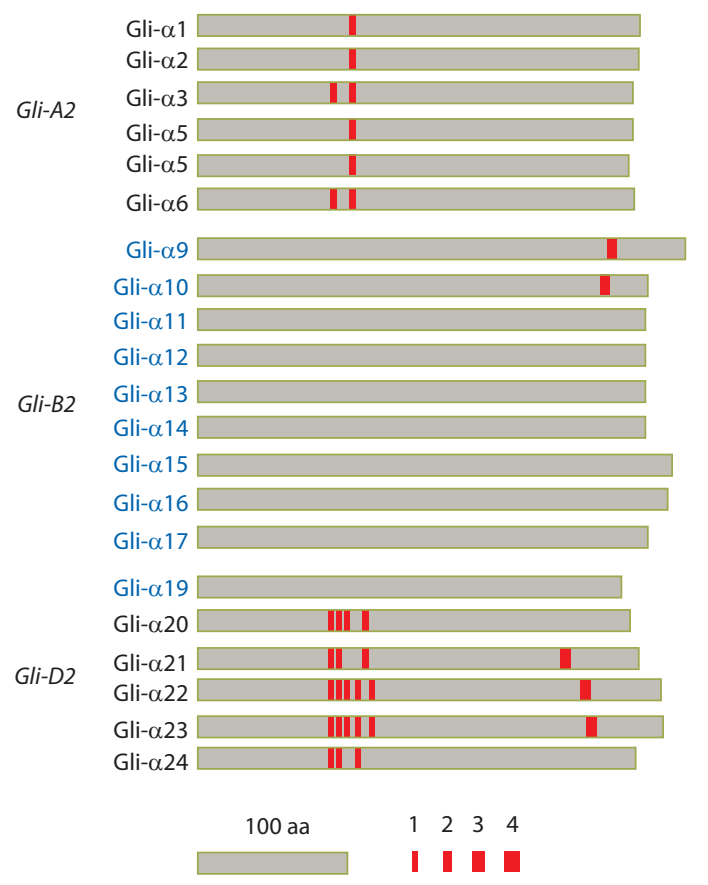

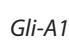

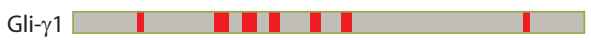

Gli-A1

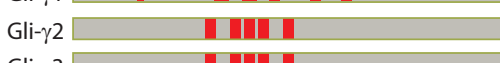

Gli- $\gamma_{3}$

Gli-B1

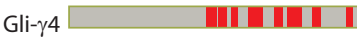

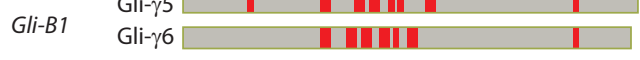

Gli- $\gamma 7 \square$

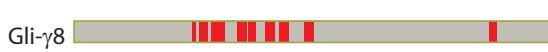

Gli-D1

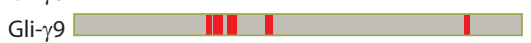

Gli- $\gamma 10 \square+\square$

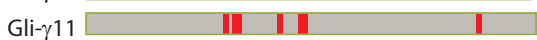

Gli-A1

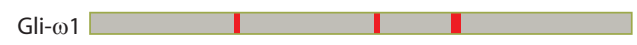

Gli-B1
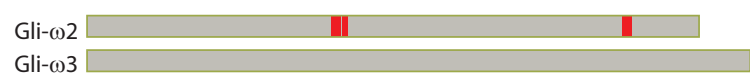

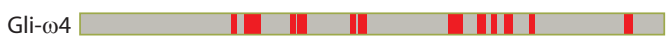

Gli-D1

Gli- $\omega 5$

Gli- $\delta 1$

Рис. 2. Представлены шесть локусов Gli (Gli-A1, Gli-B1, Gli-D1, Gli-A2, Gli-B2 и Gli-D2), кодирующих различные глиадины. Четыре закрашенных красных прямоугольника различной ширины указывают от одной до четырех копий эпитопов CD соответственно. CSTT а-глиадины (от Gli-a9 до Gli-a17 и Gli-a19) отмечены синим цветом (по: Wang et al., 2017)

остаток цистеина (C) и способные действовать в качестве терминаторов полипептидной цепи глютенина (Gianibelli et al., 2002).

D.D. Kasarda c сотрудниками (1983) использовали $\mathrm{N}$-концевые белковые последовательности для классификации $\omega$-глиадинов на основе первых трех аминокислот зрелого белка. Эти последовательности получили названия ARQ-/ARE, KEL- и SRL-типов в зависимости от первых трех AK их N-концевых последовательностей (Tatham, Shewry, 1995). Tип ARQ-/ARE кодируется генами, локализованными на хромосомах 1A и 1D. SRL-тип характерен для $\omega$-глиадинов, кодируемых генами на хромосоме 1B (Tatham, Shewry, 1995; DuPont et al., 2000). KEL-тип отличается от ARQ-типа отсутствием первых восьми аминокислотных остатков в его структуре (Hisa, Anderson, 2001).

\section{Дельта-глиадины}

Общая структура $\delta$-глиадинов пшеницы аналогична структуре, показанной на рис. 1 для ү-глиадинов. Домен SIG представляет собой сигнальный пептид, отщепляемый во время процессинга белка. Домены II и IV богаты глутамином, домен II состоит из вариаций повторяющегося мотива, а домен IV богат глутамином без четкой структуры повторения. Домены I, III и V являются неповторяемыми, причем домены III и V содержат консервативные положения цистеина, которые могут образовывать четыре внутримолекулярные дисульфидные связи, предполагающие схемы связей, аналогичные другим классам глиадина (Anderson et al., 2012).
Эпитопы глиадинов, вызывающие целиакию и пищевую анафилаксию, индуцированную физическими нагрузками

Пептиды глиадина, которые способствуют целиакии, обычно содержат один или несколько эпитопов, способных связываться с Т-клетками человека (Sollid, 2000; du Pré, Sollid, 2015; Stamnaes, Sollid, 2015). К настоящему времени выявлено более 30 эпитопов, вовлеченных в целиакию (Scherf et al., 2016; Shewry, Tatham, 2016). Разные типы глиадинов существенно различаются по содержанию эпитопов, вызывающих целиакию (Wang et al., 2017).

Пищевая анафилаксия, ассоциированная с глютеном пшеницы, индуцированная физическими нагрузками (wheat-dependent exercise-induced anaphylaxis - WDEIA), и астма пекаря - две часто встречающиеся lgE-опосредованные аллергии на пшеницу с оценкой заболеваемости от 0.33 до 1.17 \% (Cabanillas, 2020). HMW-GSs и полипептиды группы $\omega$-5 глиадинов являются основными аллергенами, связанными с WDEIA (Matsuo et al., 2004, 2005; Altenbach et al., 2018). Однако многие другие белки зерна пшеницы, например ингибиторы а-амилазы/трипсина (ATI) и белки неспецифического переноса липидов (nsLTP), также могут быть

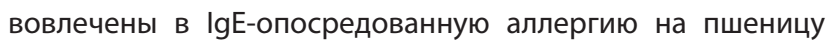
(Juhász et al., 2018; Cabanillas, 2020).

Каждую из белковых последовательностей 38 глиадинов, накопленных в зрелых зернах сорта пшеницы Xiaoyan 81, D.W. Wang с сотрудниками (2017) исследовали на предмет наличия 24 эпитопов $C D$, ранее обнаруженных в различных 
Таблица 1. Содержание CD эпитопов в а-глиадинах сорта Чайниз Спринг (по: Altenbach et al., 2020)

\begin{tabular}{|c|c|c|}
\hline Ген & $\begin{array}{l}\text { Прогнозируемый молекулярный вес } \\
\text { кодируемого белка, Да }\end{array}$ & $\begin{array}{l}\text { Количество } \\
\text { CD эпитопов }\end{array}$ \\
\hline$a-A 1$ & 31440 & 1 \\
\hline$a-A 2$ & 34471 & 1 \\
\hline$a-A 4$ & 30506 & 2 \\
\hline$a-A 5$ & 33479 & 2 \\
\hline$a-A 6$ & 30621 & 2 \\
\hline $\mathrm{a}-\mathrm{A} 8$ & 31050 & 2 \\
\hline a-A9 & 32181 & 1 \\
\hline$a-A 10$ & 29996 & 2 \\
\hline$a-B 3$ & 36206 & 1 \\
\hline$a-B 7$ & 33968 & 0 \\
\hline$a-B 8$ & 34781 & 0 \\
\hline a-B9 & 33977 & 0 \\
\hline$a-B 11$ & 31535 & 0 \\
\hline$a-B 14$ & 31413 & 0 \\
\hline a-B15 & 31284 & 0 \\
\hline$a-B 16$ & 32054 & 0 \\
\hline$a-B 17$ & 32039 & 0 \\
\hline$a-B 18$ & 31829 & 0 \\
\hline$a-B 25$ & 33818 & 1 \\
\hline$a-D 1$ & 30699 & 1 \\
\hline$a-D 4$ & 31542 & 3 \\
\hline$a-D 5$ & 33412 & $8^{b}$ \\
\hline$a-D 6$ & 31706 & 5 \\
\hline$a-D 8$ & 31435 & 6 \\
\hline a-D9 & 30810 & 6 \\
\hline$a-D 12$ & 30175 & 0 \\
\hline
\end{tabular}

глиадинах (рис. 2). У 11 ү-глиадинов имеются наиболее разнообразные и многочисленные эпитопы CD, за ними следуют пять а-глиадинов (от Gli-a20 до Gli-a24), кодируемые локусом Gli-D2, и четыре $\omega$-глиадина, кодируемые локусом

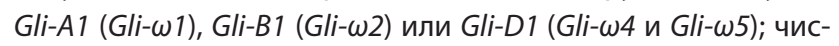
ло $\mathrm{CD}$ эпитопов в этих 20 глиадинах варьирует от 3 до 23. Токсичный пептид а-глиадина, состоящий из 33 аминокислотных остатков и несущий три эпитопа: DQ2.5-glia-a1a, DQ2.5-glia-a1b и DQ2.5-glia-a2, - также был обнаружен в последовательностях глиадинов. Расположенные на локусе Gli-D2 а-глиадины Gli-a20, Gli-a22 и Gli-a23 несут все три эпитопа, а Gli-a21 и Gli-a24 - два из трех эпитопов (см. рис. 2). Остальные 18 глиадинов содержали меньше эпитопов CD или не содержали их. В частности, два эпитопа обнаружены в каждом из восьми а-глиадинов с локуса Gli-A2 (от Gli-a1 до Gli-a6) и Gli-B2 (Gli-a9 и Gli-a10); эпитоп не присутствовал в семи а-глиадинах (Gli-a11 и Gli-a17) локуса Gli-B2, Gli-a19

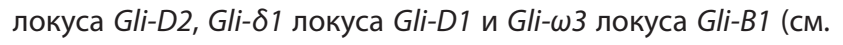
рис. 2).

S.B. Altenbach с коллегами (2020) изучили содержание эпитопов целиакии и WDEIA в различных типах глиа- динов сорта пшеницы Чайниз Спринг (табл. 1 и 2). Как и в сорте Xiaoyan 81, наиболее богаты эпитопами целиакии ү-глиадины. Значительное количество токсичных эпитопов содержат а-глиадины D-генома - a-D4, a-D5, a-D6, a-D8, a-D9. Кодируемые B-геномом $\omega$-глиадины ( $\omega$-B3 и $\omega$-B6) не содержат эпитопы целиакии, зато обогащены WDEIA эпитопами. D-геном кодирует $\omega$-глиадины ( $\omega-D 1, \omega-D 2, \omega-D 3)$, несущие по 12 или 18 CD эпитопов, а также глиадин $\omega$-D4, содержащий 33 WDEIA эпитопов.

\section{Стратегии улучшения состава глютеновых белков}

Очень важная задача на данный момент - улучшение качества муки с одновременным снижением токсичности глютеновых белков для чувствительных к этой фракции белков людей. Однако решение этой задачи не может быть простым, поскольку многие белки глютена, несущие токсичные эпитопы, важны для качества муки. Недавние исследования показали, что уменьшение накопления глиадина может снизить количество эпитопов, не влияя на качество муки, а многие белки глютена не содержат такие эпитопы. Разработано несколько стратегий для получения генотипов пшеницы, 
Таблица 2. Содержание CD и WDEIA эпитопов в $\delta-, \gamma^{-}, \omega$-глиадинах сорта Чайниз Спринг (по: Altenbach et al., 2020)

\begin{tabular}{|c|c|c|c|}
\hline \multirow{2}{*}{ Ген } & \multirow{2}{*}{$\begin{array}{l}\text { N-концевая последова- } \\
\text { тельность кодируемого } \\
\text { белка }\end{array}$} & \multicolumn{2}{|c|}{ Количество эпитопов } \\
\hline & & $C D^{a}$ & WDEIA $^{\mathrm{b}}$ \\
\hline$\delta-B 1$ & IVQL & 0 & 0 \\
\hline$\delta-\mathrm{D} 1$ & QLDP & 0 & 0 \\
\hline$\gamma-A 1$ & NIQ & 10 & 0 \\
\hline $\mathrm{Y}^{-A 3^{C}}$ & NMQ & 5 & 0 \\
\hline $\mathrm{Y}-\mathrm{A} 4^{\mathrm{C}}$ & NMQ & 5 & 0 \\
\hline $\mathrm{Y}-\mathrm{B} 1$ & NMQ & 8 & 0 \\
\hline$y-B 2$ & NMQ & 6 & 0 \\
\hline$y-B 4$ & NMQ & 10 & 0 \\
\hline$\gamma-B 6$ & NMQ & 5 & 0 \\
\hline$Y$-D1 & NMQ & 7 & 0 \\
\hline$\gamma$-D2 & NIQ & 10 & 0 \\
\hline$Y$-D3 & NMQ & 6 & 0 \\
\hline$\gamma$-D4 & NMQ & 6 & 0 \\
\hline$\omega-A 4^{d}$ & ARQ & 3 & 0 \\
\hline$\omega-B 3$ & SRL & 0 & 26 \\
\hline$\omega-\mathrm{B} 6$ & SRL & 0 & 29 \\
\hline \multirow{2}{*}{$\omega-\mathrm{D} 1$} & $\mathrm{ARQ}$ & 12 & 0 \\
\hline & KELQj & 12 & 0 \\
\hline \multirow{2}{*}{$\omega-D 2^{c}, e$} & ARE & 18 & 0 \\
\hline & KELQj & 18 & 0 \\
\hline \multirow{2}{*}{$\omega-D 3^{c, e}$} & ARE & 18 & 0 \\
\hline & KELQj & 18 & 0 \\
\hline$\omega-D 4^{d}$ & TRQ & 0 & 33 \\
\hline \multicolumn{4}{|c|}{ 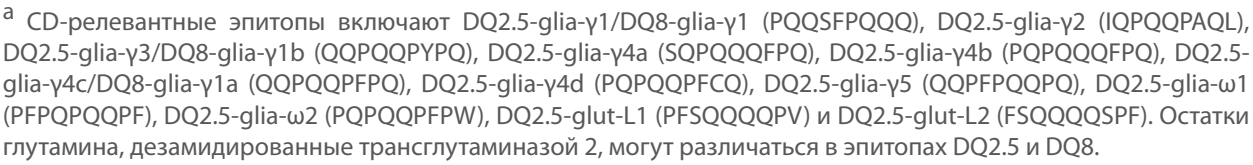 } \\
\hline \multicolumn{4}{|c|}{$\begin{array}{l}\text { b Доминантные эпитопы, участвующие в WDEIA, серьезной пищевой аллергии, индуцированной физическими } \\
\text { нагрузками анафилаксии, включают QQIPQQQ, QQFPQQQ, QQSPEQQ и QQSPQQQ. }\end{array}$} \\
\hline \multicolumn{4}{|c|}{ с Гены кодируют идентичные белки. } \\
\hline \multicolumn{4}{|c|}{ d Стоп-кодон около 3'-конца гена приводит к усеченному белку. Считается псевдогеном. } \\
\hline
\end{tabular}

безопасных для здоровья. Ниже приведено краткое изложение пяти многообещающих подходов для улучшения связанных со здоровьем характеристик путем удаления (или модификации) токсичных белков глютена с одновременным усилением функций глютеновых белков без патологических эпитопов (Wang et al., 2020).

Первый подход заключается в использовании РНКинтерференции (RNAi) для подавления синтеза всех или определенных типов глиадинов в трансгенных растениях пшеницы. В целом, линии с подавлением синтеза определенных типов глиадинов показали пониженное содержание глиадина и снижение иммуногенного потенциала глютена (Barro et al., 2016; Blechl et al., 2016; Altenbach et al., 2019). Haпример, F. Barro c коллегами (2016) подавляли экспрессию генов, кодирующих а-, $\gamma^{-}$и $\omega$-глиадины, используя комбинацию конструкций RNAi, которые устраняли эпитопы CD из высокоиммуногенных $а$ - и $\omega$-глиадинов, но не влияли на содержание общего белка и крахмала в зернах. RNAi также успешно использовали для подавления синтеза $\omega-5$ глиадинов; полученные линии показали снижение иммуногенного потенциала глютена и были рекомендованы для больных с WDEIA (Altenbach, Allen, 2011; Altenbach et al., 2015). Недавно S.B. Altenbach с сотрудниками (2019) снизили экспрессию $\omega$-1,2-глиадинов с помощью RNAi, что также привело к снижению иммуногенного потенциала глютена.

Второй подход подразумевает создание делеционных линий пшеницы, в которых отсутствует один или несколько локусов глиадина (Waga et al., 2013; Camerlengo et al., 2017). J. Waga c коллегами (2013) разработали три делеционные линии по глиадину с нулевым аллелем соответственно в Gli-D1, Gli-B1 или Gli-B2. Обнаружено снижение иммунореактивности белков глютена в делеционных линиях на 6-18 \% в сравнении с контролем дикого типа. Позже были разработаны генотипы пшеницы, лишенные как $\omega-1,2$, так и $\omega-5$ глиадинов. Полученные линии демонстрировали 30 \% снижение иммунореактивности глиадина, при этом улучшая 
содержание и прочность глютена (Waga, Skoczowski, 2014). F. Camerlengo с сотрудниками (2017) описали три делеционные линии пшеницы, лишенные локусов Gli-A2, Gli-D2 и Gli-A2/Gli-D2 соответственно. В этих линиях экспрессия a-глиадина была сильно снижена, а 33-мерный токсичный пептид глиадинов отсутствовал в линиях, лишенных Gli-D2 или Gli-A2/Gli-D2. Создано шесть делеционных линий пшеницы, в каждой из которых отсутствует один из шести глиадиновых локусов (Wang et al., 2017). Линия DLGliD2 без локyca Gli-D2 показала улучшенную функциональность теста, при этом уровень эпитопов CD значительно снизился (Wang et al., 2017).

Третий подход состоит в разработке трансгенных линий пшеницы, экспрессирующих сконструированные «глютеназы» для направленной деградации индуцирующих целиакию эпитопов в кишечнике (Osorio et al., 2019). C.E. Osorio с коллегами (2019) создали трансгенные линии пшеницы с эндосперм-специфической экспрессией эндопротеазы B2(EP-HvB2) ячменя, пролилэндопептидазы (PE-FmPep) Flavobacterium meningosepticum и пролилэндопептидазы (PE-PfuPep) Pyrococcus furiosus. Эти предварительно подготовленные детоксификаторы глютена (EP-HvB2 + PE-FmPep или EP-HvB2 + PE-PfuPep) не влияли на качество глютена, но могли разрушать эпитопы CD, содержащиеся в 33-мерном пептиде глиадина, в моделируемых желудочно-кишечных условиях (Osorio et al., 2019).

Четвертый подход заключается в снижении синтеза белков глютена путем манипулирования регуляторами, контролирующими экспрессию гена проламина (Moehs et al., 2019). S. Wen с сотрудниками (2012) продемонстрировали, что функциональное подавление пшеничного гена DME, который кодирует 5-метилцитозин ДНК-гликозилазу, приводит к снижению накопления LMW-GS и глиадинов. Недавно было показано, что устранение гомеологических генов, кодирующих WPBF (wheat prolamin-box binding factor), привело к снижению накопления LMW-GS и глиадинов, которые вместе составляли 50-60 \% белков глютена пшеницы (Moehs et al., 2019). Эти регуляторные гены служат потенциально полезными мишенями для создания линий пшеницы с низким содержанием глютена, но необходимо смягчить влияние мутаций этих генов на уменьшение размеров зерна, снижение уровня общего белка и крахмала (Moehs et al., 2019).

Пятый подход - модифицировать экспрессию генов глютена с помощью методов геномного редактирования. Геномное редактирование - быстро развивающаяся технология для внесения сайт-нацеленных мутаций в генные и регуляторные области (Yin et al., 2017; Knott, Doudna, 2018; Chen et al., 2019). В систему геномного редактирования входит нуклеаза, например Cas9 или Cpf1, и направляющая РHK (single guide RNA, sgRNA); sgRNA комплементарна целевому сайту и направляет рибонуклеарный белковый комплекс к этому конкретному сайту. В зависимости от используемых методов геномного редактирования можно получить делеции различной протяженности либо точечные замены нуклеотидов в целевом сайте (Chen et al., 2019). Редактирование генома может выполняться для одного или нескольких генов с одной или несколькими sgRNA. Используя систему CRISPR/Cas9-, удалось изменить большое количество генов а-глиадина в пшенице (до 35), при этом иммунореактивность белков глютена снизилась на 85 \% (Sánchez-León et al., 2018). A. Jouanin с коллегами (2019) подтвердили, что CRISPR/Cas9 эффективен при мутации генов а-глиадина, а также показали, что этот метод можно использовать для мутации пшеничных генов $\gamma$-глиадина.

Из различных подходов, описанных выше, редактирование генома является относительно новым, и его возможности для изменения экспрессии белка глютена еще предстоит полностью использовать. В последние годы в связи с широким развитием методов геномного редактирования появилась возможность создавать до 12 базовых замен, вставок (от 1 до $\geq 44$ п.н.), делеций (от 1 до $\geq 80$ п.н.) и их комбинаций в заранее определенном целевом сайте, контролирующем белки, входящих в состав глютена (Anzalone et al., 2019). Возможность проводить мультиплексное геномное редактирование позволяет изменять различные семейства генов, что, безусловно, будет иметь высокий потенциал в улучшении состава глютеновых белков.

\section{Заключение}

Исследования последних лет существенно улучшили понимание состава и структуры глиадинов. Были получены полногеномные сведения о типах и структурах иммуногенных глиадиновых белков, а также протестированы ценные подходы для улучшения состава глютена пшеницы. Тем не менее все еще существуют серьезные пробелы в знаниях о контроле экспрессии глиадиновых генов, а также о биохимических и биофизических механизмах, лежащих в основе взаимодействий белков глютена. В будущем сочетание геномных исследований, функциональной геномики и методов геномного редактирования ускорит фундаментальные и прикладные исследования белков глютена, что позволит эффективно разрабатывать элитные сорта пшеницы, безопасные для здоровья и обладающие глютеном высокого качества.

\section{Список литературы / References}

Труфанов В.А. Клейковина пшеницы: проблемы качества. Новосибирск: Наука, 1994.

[Trufanov V.A. Wheat gluten: quality problems. Novosibirsk: Nauka Publisher, 1994. (in Russian)]

Altenbach S.B., Allen P.V. Transformation of the US bread wheat 'Butte $86^{\prime}$ and silencing of omega-5 gliadin genes. GM Crops. 2011;2(1):6774. DOI 10.4161/gmcr.2.1.15884.

Altenbach S.B., Vensel W.H., DuPont F.M. Analysis of expressed sequence tags from a single wheat cultivar facilitates interpretation of tandem mass spectrometry data and discrimination of gamma gliadin proteins that may play different functional roles in flour. BMC Plant Biol. 2010;10:7. DOI 10.1186/1471-2229-10-7.

Altenbach S.B., Tanaka C.K., Pineau F., Lupi R., Drouet M., Beaudouin E., Morisset M., Denery-Papini S. Assessment of the allergenic potential of transgenic wheat (Triticum aestivum) with reduced levels of omega-5 gliadins, the major sensitizing allergen in wheat-dependent exercise-induced anaphylaxis. J. Agric. Food Chem. 2015;63(42):93239332. DOI 10.1021/acs.jafc.5b03557.

Altenbach S.B., Chang H.C., Simon-Buss A. Jang Y.R, Denery-Papini S., Pineau F., Gu Y. Q., Huo N., Lim S.H., Kang C.S., Lee J.Y. Towards reducing the immunogenic potential of wheat flour: omega gliadins encoded by the $D$ genome of hexaploid wheat may also harbor epitopes for the serious food allergy WDEIA. BMC Plant Biol. 2018;18:291. DOI 10.1186/s12870-018-1506-z. 
Altenbach S.B., Chang H.C., Yu X.B., Seabourn B.W., Green P.H., Alaedin A. Elimination of omega-1,2 gliadins from bread wheat (Triticum aestivum) flour: effects on immunogenic potential and end-use quality. Front. Plant Sci. 2019;10:580. DOI 10.3389/fpls.2019.00580.

Altenbach S.B., Chang H.C., Simon-Buss A., Mohr T., Huo N., Gu Y.Q. Exploiting the reference genome sequence of hexaploid wheat: a proteomic study of flour proteins from the cultivar Chinese Spring Funct. Integr. Genomics. 2020;20(1):1-16. DOI 10.1007/s10142-019 00694-z.

Anderson O.D., Litts J.C., Greene F.C. The a-gliadin gene family: 1. Characterization of ten new wheat a-gliadin genomic clones, evidence for limited sequence conservation of flanking DNA, and southern analysis of the gene family. Theor. Appl. Genet. 1997;95(1-2):50-58.

Anderson O.D., Dong L., Huo N., Gu Y. Q. A New Class of Wheat Gliadin Genes and Proteins. PLOS PLoS One. 2012;7(12):e52139. DOI 10.1371/ journal.pone.0052139.

Anzalone A.V., Randolph P.B., Davis J.R., Sousa A.A., Koblan L.W., Levy J.M., Chen P.J., Wilson C., Newby G.A., Raguram A., Liu D.R. Search-and-replace genome editing without double-strand breaks or donor DNA Nature. 2019;576(7785):149-157. DOI 10.1038/s41586-019-1711-4.

Ang S., Kogulanathan J., Morris G.A., Kok M.S., Shewry P.R., Tatham A.S., Adams G.G., Rowe A.J., Harding S.E. Structure and heterogeneity of gliadin: a hydrodynamic evaluation. Eur. Biophys. J. Biophys 2010;39:255-261. DOI 10.1007/s00249-009-0529-7.

Barak S., Mudgil D., Khatkar B.S. Biochemical and Functional Properties of Wheat Gliadins: A Review. Crit. Rev. Food Sci. Nutr. 2015;55(3):357368. DOI 10.1080/10408398.2012.654863.

Barro F., lehisa J.C., Giménez M.J., García-Molina M.D., Ozuna C.V., Comino I., Sousa C., Gil-Humanes J. Targeting of prolamins by RNAi in bread wheat: effectiveness of seven silencing-fragment combinations for obtaining lines devoid of coeliac disease epitopes from highly immunogenic gliadins. Plant Biotechnol. J. 2016;14(3):986996. DOI 10.1111/pbi.12455.

Blechl A., Beecher B., Vensel W., Tanaka C., Altenbach S. RNA interference targeting rye secalins alters flour protein composition in a wheat variety carrying 1BL.1RS translocation. J. Cereal Sci. 2016;68:172-180. DOI 10.1016/j.jcs.2016.01.009.

Cabanillas B. Review gluten-related disorders: Celiac disease, wheat allergy, and nonceliac gluten sensitivity. Crit. Rev. Food Sci. Nutr. 2020;60(15):2606-2621. DOI 10.1080/10408398.2019.1651689.

Camerlengo F., Sestili F., Silvestri M., Colaprico G., Margiotta B., Ruggeri R., Lupi R., Masci S., Lafiandra D. Production and molecular characterization of bread wheat lines with reduced amount of a-type gliadins. BMC Plant Biol. 2017;17(1):248. DOI 10.1186/s12870-017-1211-3.

Chen K., Wang Y., Zhang R., Zhang H., Gao C. CRISPR/Cas genome editing and precision plant breeding in agriculture. Annu. Rev. Plant Biol. 2019;70:667-697. DOI 10.1146/annurev-arplant-050718-100049.

DuPont F., Vensel W.H., Chan R., Kasarda D.D. Characterization of the 1B-type omega gliadins from Triticum aestivum cultivar Butte. Cereal Chem. 2000;77(5):607-614. DOI 10.1094/CCHEM.2000.77.5.607.

DuPont F.M., Vensel W., Encarnacao T., Chan R., Kasarda D.D. Similarities of omega gliadins from Triticum urartu to those encoded on chromosome $1 \mathrm{~A}$ of hexaploid wheat and evidence for their posttranslational processing. Theor. Appl. Genet. 2004;108(7):1299-1308. DOI 10.1007/s00122-003-1565-9.

du Pré M.F., Sollid L.M. T-cell and B-cell immunity in celiac disease. Best Pract. Res. Clin. Gastroenterol. 2015;29(3):413-423. DOI 10.1016/ j.bpg.2015.04.001.

Ferranti P., Mamone G., Picariello G., Addeo F. Mass spectrometry analysis of gliadins in celiac disease. J. Mass Spectrom. 2007;42(12):1531 1548. DOI 10.1002/jms.1361.

Gianibelli M.C., Masci S., Larroque O.R., Lafiandra D., MacRitchie F. Biochemical characterisation of a novel polymeric protein subunit from bread wheat (Triticum aestivum L.). J. Cereal Sci. 2002;35(3):265-276. DOI 10.1006/jcrs.2001.0401.

Hisa C.C., Anderson O.D. Isolation and characterization of wheat $\omega$-gliadin genes. Theor. Appl. Genet. 2001;103:37-44. DOI 10.1007/ s00122-001-0552-2.

Jouanin A., Schaart J.G., Boyd L.A., Cockram J., Leigh F.J., Bates R., Wallington E. J., Visser R.G.F., Smulders M.J.M. Outlook for coeliac disease patients: towards bread wheat with hypoimmunogenic gluten by gene editing of $a-$ and $\gamma$-gliadin gene families. BMC Plant Biol. 2019;19:333. DOI 10.1186/s12870-019-1889-5.
Juhász A., Belova T., Florides C.G., Maulis C., Fischer I., Gell G., Birinyi Z., Ong J., Keeble-Gagnère G., Maharajan A., Ma W., Gibson P., Jia J., Lang D., Mayer K.F.X., Spannagl M. International Wheat Genome Sequencing Consortium, Tye-Din J.A., Appels R., Olsen O.A. Genome mapping of seed-borne allergens and immunoresponsive proteins in wheat. Sci. Adv. 2018;4(8):eaar8602. DOI 10.1126/sciadv.aar8602.

Kajendran K., Chandrasekharan N.V., Hettiarachchi C.M., Wijesundera W.S.S. Molecular characterization and expression of a-gliadin genes from wheat cultivar Dacke in Bg 250 rice variety. GM Crops Food. 2019;10(2):102-114. DOI 10.1080/21645698.2019.1622990.

Kasarda D.D., Autran J.C., Lew E.J.L., Nimmo C.C., Shewry P.R. N-terminal amino acid sequences of $\omega$-gliadins and $\omega$-secalins: Implications for the evolution of prolamin genes. Biochim. Biophys. Acta. 1983;747(12):138-150. DOI 10.1016/0167-4838(83)90132-2.

Knott G.J., Doudna J.A. CRISPR-Cas guides the future of genetic engineering. Science. 2018;361(6405):866-869. DOI 10.1126/science. aat5011.

Lefebvre J., Mahmoudi N. The pattern of the linear viscoelastic behaviour of wheat flour dough as delineated from the effects of water content and high molecular weight glutenin subunits composition. J. Cereal Sci. 2007;45(1):49-58. DOI 10.1016/j.jcs.2006.06.005.

Matsuo H., Morita E., Tatham A.S., Morimoto K., Horikawa T., Osuna H., Ikezawa Z., Kaneko S., Kohno K., Dekio S. Identification of the IgE-binding epitope in omega-5 gliadin, a major allergen in wheat-dependent exercise-induced anaphylaxis. J. Biol. Chem. 2004;279(13):12135-12140. DOI 10.1074/jbc.M311340200.

Matsuo H., Kohno K., Morita E. Molecular cloning, recombinant expression and IgE-binding epitope of omega- 5 gliadin, a major allergen in wheat-dependent exercise-induced anaphylaxis. FEBS $\mathrm{J}$. 2005;272(17):4431-4438. DOI 10.1111/j.1742-4658.2005.04858.x.

Metakovsky E., Melnik V.A., Pascual L., Wrigley C.W. Gliadin genotypes worldwide for spring wheats (Triticum aestivum L.) 2. Strong differentiation of polymorphism between countries and regions of origin. J. Cereal Sci. 2019;87(6):311-317. DOI 10.1016/j.jcs.2019.04.015.

Metakovsky E., Pascual L., Vaccino P., Melnik V., Rodriguez-Quijano M., Popovych Y., Chebotar S., Rogers W.J. Heteroalleles in Common Wheat: Multiple Differences between Allelic Variants of the Gli-B1 Locus. Int. J. Mol. Sci. 2021;22(4):1832. DOI 10.3390/ijms22041832.

Moehs C.P., Austill W.J., Holm A., Large T.A.G., Loeffler D., Mullenberg J., Schnable P.S., Skinner W., van Boxtel J., Wu L., McGuire C. Development of decreased-gluten wheat enabled by determination of the genetic basis of lys3a barley. Plant Physiol. 2019;179(4):1692-1703. DOI 10.1104/pp.18.00771.

Noma S., Kawaura K., Hayakawa K., Abe C., Tsuge N., Ogihara Y. Comprehensive molecular characterizeation of the $\alpha / \beta$-gliadin multigene family in hexaploid wheat. Mol. Genet. Genomics. 2016;291(1):65-77. DOI 10.1007/s00438-015-1086-7.

Osborne T.B. The protein of the wheat kernel. Publication No. 84. Washington, DC: Carnegie Institute, 1907.

Osorio C.E., Wen N., Mejias J.H., Liu B., Reinbothe S., von Wettstein D. Rustgi S. Development of wheat genotypes expressing a glutaminespecific endoprotease from barley and a prolyl endopeptidase from Flavobacterium meningosepticum or Pyrococcus furiosus as a potential remedy to celiac disease. Funct. Integr. Genomics. 2019;19(1):123136. DOI 10.1007/s10142-018-0632-x.

Paananen A., Tappura K., Tatham A.S., Fido R., Shewry P.R., Miles M., McMaster T.J. Nanomechanical force measurements of gliadin protein interactions. Biopolymers. 2006;63(6):658-667. DOI 10.1002/ bip.20603.

Qi P. F., Wei Y.M., Yue Y.W., Yan Z.H., Zheng Y.L. Biochemical and molecu lar characterization of gliadins. Mol. Biol. (Mosk.). 2006;40(5):796-807.

Qi P.F., Wei Y.M., Ouellet T., Chen Q., Tan X., Zheng Y.L. The gamma-gliadin multigene family in common wheat (Triticum aestivum) and its closely related species. BMC Genomics. 2009;10:168. DOI 10.1186/14712164-10-168.

Rodrigues M.M.F., Martins M.M., Costa M.L. Thermal properties of gluten proteins of two soft wheat varieties. Food Chem. 2005;93(3):459-465. DOI 10.1016/j.foodchem.2004.10.023.

Sánchez-León S., Gil-Humanes J., Ozuna C.V., Giménez M.J., Sousa C. Voytas D.F., Barro F. Low-gluten, nontransgenic wheat engineered with CRISPR/Cas9. Plant Biotechnol. J. 2018;16(4):902-910. DOI $10.1111 / \mathrm{pbi} .12837 /$ 
Scherf K.A., Koehler P., Wieser H. Gluten and wheat sensitivities - an overview. J. Cereal Sci. 2016;67:2-11. DOI 10.1016/j.jcs.2015.07.008

Shewry P.R., Tatham A.S. Improving wheat to remove celiac epitopes but retain functionality. J. Cereal Sci. 2016;67:12-21. DOI 10.1016/ j.jcs.2015.06.005.

Singh M., Khatkar B.S. Structural and functional properties of wheat storage proteins: A review. J. Food Sci. Technol. 2005;42(6):455-471.

Singh S., Singh N., MacRitchie F. Relationship of polymeric proteins with pasting, gel dynamic and dough empirical-rheology in different Indian wheat varieties. Food Hydrocoll. 2011;25(1):19-24. DOI 10.1016/ j.foodhyd.2010.05.001.

Sollid L.M. Molecular basis of celiac disease. Annu. Rev. Immunol. 2000;18:53-81. DOI 10.1146/annurev.immunol.18.1.53.

Song Y., Zheng Q. Influence of gliadin removal on strain hardening of hydrated wheat gluten during equibiaxial extensional deformation. J. Cereal Sci. 2008;48(1):58-67.

Stamnaes J., Sollid L.M. Celiac disease: Autoimmunity in response to food antigen. Semin. Immunol. 2015;27(5):343-352. DOI 10.1016/ j.smim.2015.11.001.

Tack G.J., Verbeek W.H., Schreurs M.W., Mulder C.J. The spectrum of celiac disease: epidemiology, clinical aspects and treatment. Nat. Rev. Gastroenterol. Hepatol. 2010;7(4):204-213. DOI 10.1038/nrgastro.2010.23.

Tatham A.S., Shewry P.R. The S-poor prolamins of wheat, barley and rye. J. Cereal Sci. 1995;22:1-16.

Veraverbeke W.S., Delcour J.A. Wheat protein composition and properties of wheat glutenin in relation to breadmaking functionality. Crit. Rev. Food Sci. Nutr. 2002;42(3):179-208. DOI 10.1080/10408690290825510.
Waga J., Skoczowski A. Development and characteristics of $\omega$-gliadinfree wheat genotypes. Euphytica. 2014;195:105-116. DOI 10.1007/ s10681-013-0984-1.

Waga J., Zientarski J., Szaleniec M., Obtulowicz K., Dyga W., Skoczowski A. Null alleles in gliadin coding loci and wheat allergenic properties. Am. J. Plant Sci. 2013;4(1):160-168. DOI 10.4236/ajps.2013.41021.

Wang D.W., Li D., Wang J., Zhao Y., Wang Z., Yue G., Liu X., Qin H., Zhang K., Dong L., Wang D. Genome-wide analysis of complex wheat gliadins, the dominant carriers of celiac disease epitopes. Sci. Rep. 2017;7:44609. DOI 10.1038/srep44609.

Wang D., Li F., Cao S., Zhang K. Genomic and functional genomics analyses of gluten proteins and prospect for simultaneous improvement of end-use and health-related traits in wheat. Theor. Appl. Genet. 2020;133(5):1521-1539. DOI 10.1007/s00122-020-03557-5.

Wellner N., Bianchini D., Mills E.N.C., Belton P.S. Effect of selected hofmeister anions on the secondary structure and dynamics of wheat prolamins in gluten. Cereal Chem. 2003;80(5):596-600. DOI 10.1094/ CCHEM.2003.80.5.596.

Wen S., Wen N., Pang J., Langen G., Brew-Appiah R.A., Mejias J.H., Osorio C., Yang M., Gemini R., Moehs C.P., Zemetra R.S., Kogel K.H., Liu B., Wang X., von Wettstein D., Rustgi S. Structural genes of wheat and barley 5-methylcytosine DNA glycosylases and their potential applications for human health. Proc. Natl. Acad. Sci. USA. 2012;109(50):20543-20548. DOI 10.1073/pnas.1217927109.

Wieser H. Chemistry of gluten proteins. Food Microbiol. 2007;(2):115119. DOI 10.1016/j.fm.2006.07.004.

Wrigley C., Bekes F., Bushuk W. (Eds.). Gliadin and glutenin: the unique balance of wheat quality. St. Paul: AACC International, 2006.

Yin K., Gao C., Qiu J.L. Progress and prospects in plant genome editing. Nat. Plants. 2017;3:17107. DOI 10.1038/nplants.2017.107.

Конфликт интересов. Авторы заявляют об отсутствии конфликта интересов.

Поступила в редакцию 04.11.2021. После доработки 25.11.2021. Принята к публикации 29.11.2021. 